\title{
Dave Cottam elected new Chair of GDPC
}

Birmingham's Dave Cottam has been elected Chair of the General Dental Practice Committee, following a special meeting held in Wimpole Street.

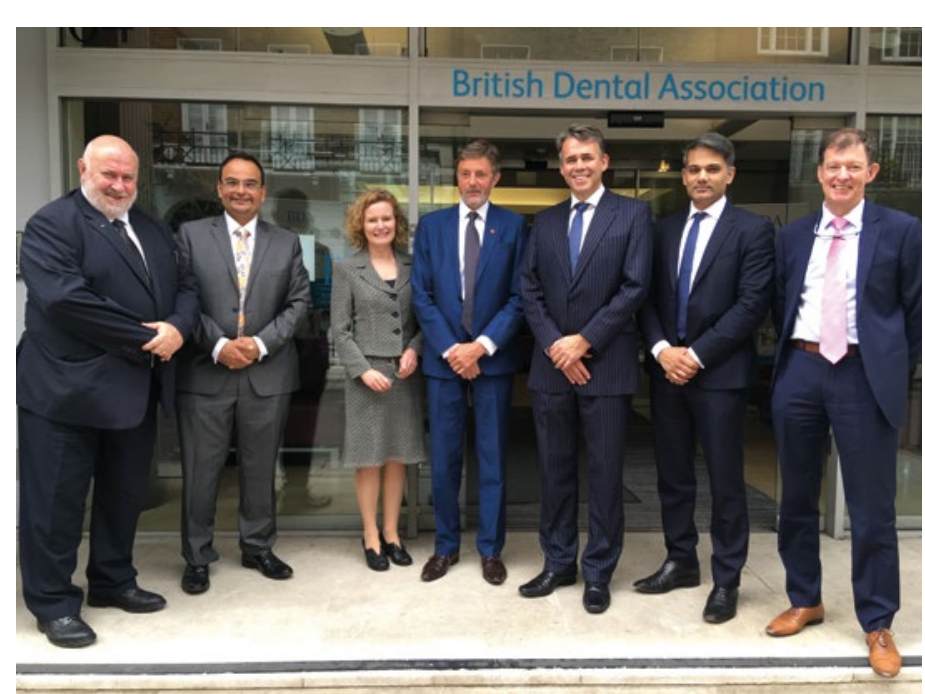

He will lead negotiations with government over rollout of a reformed GDS contract.

Dave is a specialist in oral surgery, and previously served as Vice Chair of the

GDPC. He has also served as chair of Birmingham LDC and President of Central Counties Branch. Currently an associate, he has four decades of experience treating both NHS and private patients.

Shawn

Charlwood was joined as Vice Chair by former LDC Conference Chair Vijay Sudra. Shiv Pabary and Leah Farrell, with Nick Stolls and Nilesh Patel remain as members of the Exec.

Dave Cottam said: 'It is a privilege to serve as chair of the GDPC, and to give a voice to over 30,000 colleagues in high street practice.

'We need a paradigm shift in the way NHS dentistry is delivered across the country. I have already stressed the urgency on contracts directly to the new team at the Department of Health and Social Care. We cannot allow the pedestrian pace of reform in both England and Wales to continuing failing our patients.

'But colleagues across the UK - in NHS, mixed and private practice - are all under pressure. We cannot simply wait and react to the latest blow. Our duty is to make change happen for GDPs.'

\section{Here has been an advertisement.}

\section{SPRINGERNATURE}

